\title{
Ethical considerations in the treatment of childhood obesity
}

This article was published in the following Dove Press journal:

Medicolegal and Bioethics

5 March 2015

Number of times this article has been viewed

\author{
Mandy L Perryman' \\ Kara A Sidoti ${ }^{2}$ \\ 'Department of Leadership and \\ Counselor Education, University of \\ Mississippi, MS, USA; ' ${ }^{2}$ ynchburg \\ College, Lynchburg, VA, USA
}

Correspondence: Mandy L Perryman Department of Leadership and Counselor Education, The University of Mississippi, PO Box 1848, 143 Guyton Hall, University, MS 38677-1848, USA

$\mathrm{Tel}+\mathrm{I} 6629157816$

Fax + I 6629157230

Email perryman@olemiss.edu
Abstract: Rates of obesity in children and adolescents appear to be stabilizing, though the prevalence of extreme obesity in this population remains fairly consistent at $4 \%$. Childhood obesity contributes to serious health complications, such as hypertension, orthopedic problems, hormonal imbalances, and adult obesity. Psychological, as well as social issues are also common comorbid conditions to childhood obesity. Families and health care providers have limited options in regard to treating childhood obesity, some of which come with complications and potentially severe consequences. Currently, though there are no standardized recommendations or guidelines for the treatment of childhood obesity, it is routinely suggested that families and medical practitioners attempt to decrease weight through family-based treatment prior to the prescription of medications or bariatric surgery. Family-based treatment options include therapy, psychoeducation, and lifestyle modification for the entire family, rather than solely focused on the overweight child. Using pharmacotherapy to treat childhood obesity has shown to be effective in decreasing body mass index, along with changes in nutrition and activity. Use of these medications for managing obesity comes with undesirable side effects involving gastrointestinal and cardiovascular systems and raises concerns about malnutrition. Although bariatric surgery has increased over the last several years and has shown some success in the treatment of obesity, minor to severe medical complications have surfaced. Low calcium levels, unexpected pregnancies, risk of death postoperation, and the development or resurfacing of psychological disorders, such as binge eating disorder and depression, have occurred after bariatric surgery. The health of the child, efficacy of weight loss alternatives, risks and benefits associated with those choices, and the decision-making ability of minors must all be considered when determining the best treatment option for obese children.

Keywords: childhood obesity, bariatric surgery, family-based treatment, pharmacology, bioethics

\section{Prevalence of childhood obesity}

Rates of childhood obesity have more than tripled over the last 3 decades, although recent studies have shown some stabilization in most age groups. ${ }^{1}$ While school-based programs focused on increasing physical activity and better nutrition choices may be contributing to the deceleration of this epidemic, approximately $4 \%$ of US children continue to be categorized as extremely obese, outnumbering the number of children diagnosed with cancer, cystic fibrosis, HIV, and juvenile diabetes combined. ${ }^{2}$ Children of low-income families continue to be nearly three times at a greater risk of obesity than children in middle-income families. In addition, African-American and Hispanic children have significantly higher rates of obesity when compared to Caucasian children. ${ }^{3}$ Across ethnic and socioeconomic populations, $25 \%$ of 17 - to 24 -year olds 
are currently ineligible to enlist in the military due to being overweight. ${ }^{4}$ Therefore, childhood obesity continues to present substantial and complex problems with limited options offering viable, long-term solutions.

\section{Physical and psychosocial effects of childhood obesity}

It is estimated that half to three-quarters of obese children and adolescents will become obese adults. That percentage rises to $80 \%$ if one parent is obese as well. ${ }^{5}$ Common comorbid physical conditions to obesity are hypertension, sleep apnea, gall bladder disease, orthopedic problems, and hormonal imbalances. ${ }^{3,6,7}$ The National Health and Nutrition Examination Survey revealed that approximately half of the overweight teens evaluated had at least one risk factor for cardiovascular disease and nearly one of four teens of average and aboveaverage weight were at significant risk for type 2 diabetes. $^{8}$

In addition to physical consequences, there are also many psychological implications of obesity on children and adolescents, such as being stigmatized, socially marginalized, having a poor self-concept and low self-esteem, along with acquiring a low health-related quality of life. ${ }^{2,9}$ Health-related quality of life is "the physical, psychological, and social domains of health that are influenced by experiences, beliefs, expectations, and perceptions." 10 Schwimmer et al ${ }^{11}$ found lower reports of health-related quality of life in obese children than among children with cancer.

Meta-analysis by Russell-Mayhew et al ${ }^{12}$ revealed that there are many psychosocial issues associated with childhood obesity, such as depression, anxiety, body dissatisfaction, unhealthy weight control practices, emotional problems, weight-based teasing, and peer victimization. Some studies show obese children are more likely to suffer from Attention deficit hyperactivity disorder (ADHD), conduct disorder, and learning disabilities than their nonobese peers. ${ }^{3}$ Though the direction of the relationship between these mental health factors and obesity has not been empirically determined, the correlation has been well-established.

\section{Etiologies of childhood obesity}

Though most people associate pediatric obesity with overeating and a consistent lack of physical activity, and both are certainly contributing factors, other origins of this epidemic are often overlooked. ${ }^{13,14}$ The quality of available foods and beverages, means for physical activity, and patterns of sleep, as well as parental modeling and involvement, all influence childhood obesity. ${ }^{14-16}$ According to Spruijt-Metz, ${ }^{16}$ a discernable shift in food marketing has changed nutrition choices for children, with an emphasis on high-caloric, energy-dense, refined foods, such as fast food and soft drinks. The unregulated access to vending machines in schools, which is positively correlated to higher BMIs (body mass indexes), ${ }^{16}$ is one illustration of food availability that did not exist just one generation prior. Conversely, physical education in the school system was deemed an important component of a child's overall learning until recently. "Considering the current situations of physical education in schools, actions are needed to promote a quality physical education program to confront childhood obesity problems, which could equip children and adolescents with the fitness levels, knowledge, motor skills, and personal/social skills they need to be active now and in the future." 17 Though some attention has been given to school-based programs focused on increasing students' movement, some studies show that children aged 6-18 are not meeting the physical activity guideline from 2008, which includes 60 minutes of exercise per day, and as children get older, the time spent on physical activities continues to decline. ${ }^{14,16}$

In addition to diet and activity levels, sleep is another physical system linked to the development and maintenance of childhood obesity. It is recommended that children need a minimum of 8 hours of sleep each night, less puts the child at three times the risk of obesity due to a change in ghrelin and leptin, both of which regulate appetite and feelings of satiation. ${ }^{16}$ When children are deprived of sleep, there is an increase in eating highly palatable, energy-dense foods and a decrease in physical activity, due to the lack of energy. ${ }^{16}$ Typically, sleep apnea is considered a consequence of obesity; however, obstructive sleep apnea may also contribute to weight gain, altering appetite levels and eating routines, especially late evening and night eating. It may also cause excessive drowsiness during the day, impeding physical activity. $^{7}$

Parenting styles and family values have been found to influence the way in which children eat. Some research shows that an authoritative parenting style decreases the risk of obesity and increases the amount of healthy foods eaten when compared to other types of parenting. ${ }^{15,16}$ However, overly controlling feeding practices may negatively impact the child's food selections, as well as the amount of food consumed and eating frequency, consequently affecting the child's weight. ${ }^{15}$ A common family value is shared meal times. Children benefit from eating meals with their family due to an increase in fruits and vegetables eaten, better 
psychosocial health, and less weight control behaviors. These experiences may be 20 minutes, but meal times with family comes with some protective factors, including positive family and parent interactions and food-related dynamics, both of which are associated with a decreased risk of childhood obesity. Researchers suggest increasing the number of family meals to promote positive group enjoyment, facilitate stronger relationships and encourage better communication skills. ${ }^{18}$

\section{Diagnosing childhood obesity}

Categorizing children as obese generates its own set of ethical concerns. BMI, a ratio of weight to height, has traditionally been used to assess overweight in adults and continues to be the most popular standard for gauging obesity. However, as BMI is now consistently used for measuring the child and adolescent population, it has become criticized due to the physical growth and development expected in this group. ${ }^{19}$ The child's BMI and sex are charted and compared to others in that age range to determine what percentile to classify the child, with above the 85 th as at risk for overweight and over the 95 th as obese. The growth charts used in this process are becoming dated and were normed on an American population back in the $60 \mathrm{~s}, 70 \mathrm{~s}$, and $80 \mathrm{~s} .{ }^{19,20}$ Given the limitations of the assessment of obesity in children, it is also important to acknowledge that obesity is a socially created classification, ideally used to help identify individuals needing assistance. ${ }^{21}$ But, like most systems used to categorize people, it is not absolute. Every person within each category does not identify with the label given and/or believe help is needed.

In 2013, the American Medical Association acknowledged obesity as a disease. The benefits of this decision are more support for research, as well as treatment and prevention of obesity, along with the public message of reducing individual liability and in turn, social stigma. ${ }^{22}$ Only 5 years prior, a panel of experts, tasked by the Obesity Society, chose not to characterize obesity as a disease, but rather a serious and complex condition with various contributing factors that leads to numerous physical, emotional, and social problems. ${ }^{23}$ Hoyt et $\mathrm{al}^{22}$ found that sending the message that obesity is a disease strengthened some campaigns to increase body image satisfaction, but weakened some efforts to help obese individuals choose lower calorie foods. Due to the vulnerability and impressionable nature of obese children, as well as their ongoing physical and emotional development, how they are diagnosed has important implications for effective treatment.

\section{Treatment options for childhood obesity}

There are several treatment modalities that may be explored when addressing childhood obesity, including pharmacotherapy, family-based treatment, as well as bariatric surgery. ${ }^{24}$ Selecting the appropriate treatment option and then implementing it is a complex and at times, difficult process. The use of pharmacotherapy in regard to treating childhood obesity may come with severe consequences and/or side effects if prescribed. ${ }^{25}$ It has been suggested that using family-based treatment options, prior to employing medical and surgical interventions is prudent given the negative side effects and even potential lethality of these choices. ${ }^{26}$ Though these modalities may come with negative consequences, there are several positive aspects to these approaches. Providers and families who have attempted family-based weight loss treatment and were unsuccessful may have no option, given the severity of their comorbid health conditions, but to attempt other treatments, such as medications to manage weight loss, some of which have been shown to be effective in managing childhood obesity. ${ }^{24,25,27}$ In addition, bariatric surgery comes with risks and benefits as well. Given the relatively recent use of surgical intervention for obese children, only some enduring issues have been discovered thus far, such as substance abuse, eating disorders, and malnutrition. ${ }^{26,28-30}$ However, some families may feel as though the benefits outweigh the risks with surgery and that it offers the only way to decrease significant weight and health problems.

\section{Pharmacotherapy}

There are several medications used in the United States, as well as internationally, for managing obesity in adolescents, including Orlistat, Sibutramine, and Metformin. ${ }^{24,28}$ Orlistat blocks fat absorption in the intestine by inhibiting lipase activity. ${ }^{24}$ It reduces gastrointestinal absorption of fat by $30 \% .{ }^{31}$ Sibutramine conversely, "promotes satiety and enhances energy expenditure by inhibiting the reuptake of the neurotransmitters noradrenaline and serotonin." ${ }^{24(\mathrm{p} 258)}$ According to the literature, it is recommended that this medication be prescribed to those 16 years and older. ${ }^{24}$ Lastly, Metformin, studied in adolescents 10 years and older, is an insulin sensitizer for treating diabetes and polycystic ovary syndrome, which may also act as an appetite suppressant. ${ }^{24,26}$

Orlistat is the only long-term, US Food and Drug Administration (FDA)-approved medication for treating obesity in adolescents 12 years and older. ${ }^{27,31,32}$ Metformin is not used in the United States due to lack of approval by 
the US Food and Drug Administration (FDA). ${ }^{26}$ Sibutramine was removed from the market in Europe and is restricted in the United States due to cardiovascular issues. ${ }^{25,28}$ Though Sibutramine is limited in the United States and Orlistat is FDA approved, both raise safety concerns and acknowledge adverse side effects. ${ }^{27}$

When taking Sibutramine, some participants experienced tachycardia, dry mouth, headache, constipation, dizziness, insomnia, and hypertension. ${ }^{24,25}$ Most side effects experienced when taking Orlistat are gastrointestinal, such as steatorrhea (fat excretion in stools), oily stools, abdominal pain, fecal urgency, nausea, hyper-defecation, flatulence, diarrhea due to fat excretion, and/or bowel incontinence. ${ }^{25,31}$ Another concern regarding the intake of Orlistat is the malabsorption of fat-soluble vitamins, which is particularly distressing in the adolescent population due to normative, developmental growth. ${ }^{24,31}$

The literature examined suggests medication usage be considered when all other treatment options have been exhausted and should be used in combination with other lifestyle modifications, such as increased physical activity and changes in diet. ${ }^{24,31}$ The effectiveness of weight loss medications varies. In one study, Orlistat has been shown to be safe and effective in weight reduction in the obese adolescent population for up to 1 year. ${ }^{33}$ According to the XENical in the Prevention of Diabetes in Obese Subjects study, participants experienced a decrease in BMI, cholesterol, blood pressure, and waist circumference. ${ }^{34}$ Metformin has shown to improve body composition and metabolic parameters; however, there is a lack of evidence for treating obesity in adolescents. ${ }^{24,35}$ Sibutramine, along with diet, exercise, and lifestyle changes, is shown to be effective in decreasing BMI in obese adolescents. ${ }^{25}$

Although the only FDA-approved medication for obese adolescents in the United States is Orlistat, other medications, such as Sibutramine, are prescribed, albeit in a conservative manner. Lifestyle, diet, and exercise changes should all be implemented in conjunction with medication and families are encouraged to be involved to better increase the chances of sustainable weight loss in obese adolescents. ${ }^{26}$

\section{Family-based treatment}

Incorporating the family into obesity treatment for children is essential in decreasing unhealthy eating habits, deterring possible negative psychological outcomes, and incorporating healthy lifestyles. Family-based treatment interventions have been found to be effective in treating pediatric obesity. ${ }^{36}$ "Family-based interventions are community-based programs that empower the entire family to reduce sedentary behaviors and to increase good nutritional choices." ${ }^{37(\mathrm{p} 2)}$ According to Sung-Chan et al, ${ }^{38}$ there are four types of family-based treatment interventions: family-based lifestyle intervention, family-based lifestyle intervention with the incorporation of parent education, family therapy, and family therapy with psychoeducation.

Family-based lifestyle intervention is an implementation of a healthy lifestyle that involves the child and at least one parent or caregiver. ${ }^{38}$ This treatment option emerges from the perspective that the parent provides resources for the child and maintains the environment in which the child lives; therefore, the parent or guardian is responsible for creating a healthier lifestyle for the child. In this family-based intervention, parents are educated on self-monitoring, goal setting, relapse prevention, and behavioral contracting. ${ }^{38}$ According to Dolinksy et al, ${ }^{26}$ lifestyle modification is difficult for the child and family, but is imperative prior to implementing any type of obesity management plan. Lifestyle modification, including dietary changes, increased physical activity, and reduction of sedentary behaviors are all shown to be effective in treating overweight and obese adolescents, especially when at least one parent or caregiver is also actively participating in the lifestyle change. ${ }^{26}$

Because parents or guardians act as decision makers, including choices regarding nutrition and activity, including the whole family in treatment increases the chances of long-term lifestyle changes, as well as weight loss. ${ }^{39}$ In one study, the family-based behavioral weight control program implemented showed significant weight loss at 6 months and showed a decrease in medical risks at 12 months. This program included 20 meetings at 1 hour each for 6 months, educational material, six booster sessions, increase in physical activity, realistic goal setting, minimization of emotional eating, coping skills in regard to teasing, promoting body image, and encouragement for adults in the program to lose weight. ${ }^{40}$ In another study, completed by Levine et al, ${ }^{36}$ researchers found that the children who completed the family-based behavioral treatment lost a significant amount of weight, but half of the children did not maintain weight loss after the program ended. But, researchers also found that depression and anxiety symptoms decreased and were sustained after completion of the program.

Family therapy, an additional family-based treatment option, is also used to manage weight loss. This modality attempts to strengthen the relationship between parent and child in order to better manage the child's weight program. Research shows there is a connection between dysfunctional family systems and an increase in development of 
depression, substance abuse, anxiety, and eating disorders. ${ }^{38}$ Additionally, psychoeducation based on family variables (such as nurturance, cohesion, conflict resolution, competence, satisfaction, and warmth) is suggested in weight loss programs to increase effectiveness. ${ }^{38}$

Family-based interventions also include altering thought patterns to re-learn behaviors related to eating habits. ${ }^{37,39}$ Dieting is a learned behavior that is first introduced by parents or guardians to children at a young age. For example, if a parent is overweight, makes negative remarks about himself or herself, and/or discusses and attempts dieting, this is then modeled for the child, therefore increasing the likelihood of unhealthy self-esteem and body image of the child. ${ }^{37,39}$

\section{Bariatric surgery}

In the last 15 years, adolescent bariatric surgery has increased significantly with some reporting as much as a 300\%-500\% upsurge, with the largest rise from 2000-2003. ${ }^{41,42}$ Commonalities in these findings lie in the demographics, with a larger number of patients being female, privately insured, with an average age of 16 years, predominantly Caucasian, from high-income families. However, Medicaid use for these types of surgeries has increased from 7.7\% in 2003 to $17.2 \%$ in $2009 .{ }^{41}$ Also, while some researchers found adolescent patients were more likely to receive bypass surgery, ${ }^{41-43}$ one recent California study found gastric banding had increased, while bypass procedures had decreased. ${ }^{44}$ Others report sleeve surgeries are becoming more readily selected $^{45}$ and have been performed on children as young as 7 years old. ${ }^{43}$ Algahtani et $\mathrm{al}^{46}$ found that sleeve surgeries were performed on 108 patients aged 5-21 years, with a mean age of 13.9 years, with $83.3 \%$ having co-occurring issues, such as Prader-Willi syndrome, Bardet-Biedl syndrome, and Down syndrome. Of those, approximately $62 \%$ were younger than 14 years old.

While bariatric surgery has shown some success and even remission in treating many of the medical conditions associated with childhood obesity, some minor to severe medical complications due to surgery have been reported, such as a greater risk of unexpected pregnancy following the operation. ${ }^{21}$ Also, low levels of calcium, as well as vitamins and iron, are common after bariatric surgery, ${ }^{47}$ and "adolescence is a critical time for bone mass accumulation, with up to $50 \%$ of adult bone mass achieved during this period. Calcium and vitamin D are vital for optimal bone mineral accrual in the developing skeleton." ${ }^{47}$ Inge $^{48}$ reported that some disadvantages of bypass surgery are not only deficiencies in iron, calcium, and B vitamins but also a $0.5 \%$ risk of death postoperation. A higher BMI increases the risk of operative complications and death. ${ }^{49}$

Of those presenting for bariatric surgery, Muller et $\mathrm{al}^{29}$ found nearly $25 \%$ qualified for a diagnosis of binge eating disorder. Postsurgery, those symptoms were significantly reduced, but for some, symptoms became even more severe and extreme dieting behaviors emerged. Identifying eating disorders and disordered eating can become even more complicated after surgery. ${ }^{29}$ Also, alcohol abuse has been shown to resurface postsurgery for some individuals. ${ }^{30}$ While it is not possible to determine if participants were already at higher risk of suicide than those not opting for surgery prior to their procedure, postsurgery bariatric patients have been found to be significantly more likely to commit suicide..$^{50}$

Groven et $\mathrm{al}^{51}$ explored some of the more understated effects of bariatric surgery and found a persistent lack of energy, lower quality of life, and a psychological disconnect from the patient's new, altered body. While there have not yet been many studies examining the psychosocial outcomes of bariatric surgery, of the few available, depression and less self-acceptance postsurgery have been found in adolescents. ${ }^{21}$ While efficacy and safety continue to be a concern with bariatric surgery, Golomb and Koperski ${ }^{52}$ warn there are "significant immediate health risks, uncertain long-term implications, unending monitoring, prospects for reoperation, and a lifetime of side effects" from surgical obesity intervention.

General practitioners appear ambivalent about the effectiveness of obesity treatment options and attribute the condition to psychological and behavioral factors compared to lay people who favor a biological cause to obesity. Physicians reported that patients wanted them to take responsibility of their weight problems, though they did not feel it was in their professional domain with only 3\% referring for behavior treatment for obesity and $23 \%$ referring for surgery. ${ }^{53}$ van Geelen et $\mathrm{al}^{54}$ found that nearly half of the pediatricians surveyed would not refer an obese child for bariatric surgery and the majority of the other half would make the referral only when the patient reached adult age. Another recent study found similar results in physician recommendations for bariatric surgery with a minimum age of endorsement of 18 years with nearly all the participants indicating a need for a weight management program prior to surgery, but the program length suggested varied from 3 months to 5 years. Few respondents felt surgery should be considered for those under 15 years of age. Additionally, $17 \%$ of the sample indicated a different minimum age for boys versus girls with girls being 1.5 years younger. ${ }^{55}$ Iqbal et $\mathrm{al}^{56}$ indicated the resistance to refer was 
likely due to apprehensions involving surgery complications and a lack of longitudinal research results.

The National Institutes of Health Consensus Statement Panel suggests bariatric surgery is the most effective tool for obesity treatment and while surgical candidates should have attempted traditional forms of weight loss, they should not be required to complete a formal program as precondition for surgery. The Panel also proposes the need for a comprehensive medical evaluation, taking into account the candidate's physiological maturity (having reached $95 \%$ or more of his or her predicted adult stature), as well as an assessment of the candidate's ability to participate in the decision-making process (requiring satisfactory cognitive and psychological development), ${ }^{57}$ for which there are no established and accepted standards. ${ }^{54}$

\section{Ethical considerations}

When deciding which treatment option is most beneficial for the obese child, the primary consideration is if the health of the child is being compromised by the obesity. Then the caregiver must determine the effectiveness of other available weight loss options and finally, the executive capacity of the child must be evaluated. Meaning, it must be decided if the child understands all aspects of the intervention, such as surgical procedures, the risks and benefits of surgery, the likelihood of the risks and benefits occurring, and the lifelong commitment to surgical follow-up. ${ }^{58}$ While the health care professional must determine if the child has this ability, it is the parent or guardian who must give consent for the child. This becomes problematic when parents and their children do not agree on surgery to treat obesity. Parents may focus on the perceived negative physical and psychological consequences of their child's obesity and attempt to persuade the child's assent. ${ }^{47}$

\section{Parents as decision-makers}

Zeller et al ${ }^{59(\mathrm{p} 149)}$ found that the "overwhelming majority" of caregivers of pediatric bariatric surgery patients were obese or extremely obese and for those who were not, $25 \%$ had themselves undergone bariatric surgery as had their caregiving partner. These findings suggest that caregivers may have a distinct bias when choosing an effective treatment option for their obese child, and a family approach to bariatric surgery could have considerable benefits and challenges. In contrast, interviews conducted with children and parents regarding pediatric bariatric surgery, found that some parents felt surgery was "wrong or too easy a solution for their child's actual problem", while other parents reported feelings of guilt for their child's obesity. ${ }^{54}$ Some children described their obesity as a weakness and lack of willpower and conveyed a "need to overcome one's actual problems in the "right way". 54 This qualitative information highlights a stigma associated with bariatric surgery from children and parents, which may lead to other problematic issues, like dieting. Weight control behaviors of parents have been correlated to lower body satisfaction and more severe dieting in adolescents. Their family climate has been shown to have more adolescent overeating, less family cohesion, and low adaptability. In addition, low body satisfaction and self-esteem in parents were indicative of lower body satisfaction and greater importance of thinness in adolescents. ${ }^{60}$ As caregivers are making decisions on behalf of children, it is important to consider these selections are being processed through the parents' own experiences and perceptions around obesity. Support from health care professionals through the decision-making process for treatment is beneficial for the parent and the obese child.

\section{Health care professionals as stakeholders}

The guiding moral principles, which serve as a foundation for ethical standards in the helping professions, are autonomy, nonmaleficence, beneficence, justice, fidelity, and veracity. ${ }^{61}$ As these tenets are applied to treatment decisions for childhood obesity, there is much to consider. Autonomy, or the rights of patients to independently self-govern and select options based on their own wishes, is forfeited as children are not able to make health-related choices. Autonomy would allow the child to create and implement a plan, as well as actively pursue that chosen destiny; ${ }^{58}$ however, legally and ethically, that responsibility falls to the parent. This calls into question the parent's ability to make decisions in the best interest of the obese child, given the present health condition. ${ }^{21}$ Are the same people who are liable for electing the best treatment option for the obese child also accountable for the child's weight, given their genetic contribution and/ or the environment they provide to the child? If so, it stands to reason that the parent's choice cannot be unbiased or that it unequivocally leads to the best health outcome for every child. While there is the assumption that parents inherently know what is best for their child, ${ }^{21}$ it is a social conjecture nonetheless. Caniano ${ }^{62}$ suggests that making treatment decisions, especially when considering bariatric surgery, should be a process in which questions and concerns by the patient and caregiver are addressed over several months by the physician. Further, she tasks the treatment team to evaluate 
informed consent by asking "Does the patient feel coerced by others, be they parents, peers, or physicians to agree to the bariatric procedure?"62(p189)

Nonmaleficence, or to do no harm, is another obligation helping professionals have to refrain from actions that risk hurting patients. When contemplating treatment options for the obese child, which interventions do no harm? There are varying degrees of physical, as well as social and emotional, risks associated with pharmacotherapy, family-based treatment, and bariatric surgery. The least invasive of these is family-based treatment for childhood obesity; however, new research has found that parent motivation is a significant factor in this type of intervention, ${ }^{63}$ as is parental weight loss. ${ }^{64}$ While this type of interdependency is essential to the success of a systemic approach, it can also create an atmosphere of competition and antagonism, which can strain family dynamics. Also, some family-based strategies do not address teasing and social skill deficits that can also have hurtful consequences for the obese child. ${ }^{36}$ While the risks of medication and surgery have been addressed prior, and must be compared to the hazards of obesity, it is important to note the greatest potential for maleficence lies in these medical remedies. "For pediatric patients who are morbidly obese, the ethical principle of beneficence requires that physicians seek to reverse the physical and psychological derangements that interfere with well-being." ${ }^{62(\mathrm{p} 187)}$ When pediatric patients are not given the opportunity to explore less aggressive means to lose weight and reduce comorbid conditions through dietary and exercise changes, and not well-informed of long-term follow-up required by surgery or undesirable side effects of medications, beneficence is violated.

Professionals must do their due diligence to ensure that they give evenly to others, resources are accessible to all in need, and that those in their care receive equitable, just treatment. In the field of childhood obesity, treatment options vary in their cost and availability. Socioeconomic status dictates who is a candidate for bariatric surgery, while insurance allowance for pharmaceuticals determines what individuals can afford medications for obesity. ${ }^{21,62}$ Family-based treatment often requires professional leadership, educational materials, activity equipment, and available facilities, which can be a financial burden. These programs often receive grant or government funding, offsetting or negating the cost for family members.

As helping professionals are establishing dedicated relationships with families and patients, trust is paramount. Fidelity is accomplished when the treatment team takes a comprehensive approach and understands how to best meet the obese child's goals toward weight loss and health promotion and follows through on their commitment. The family and child are also confiding in that team based on their advertised knowledge, skill, and expertise in the area of pediatric obesity treatment. Because medical interventions for obesity are still relatively new, further investigation is needed to determine best practice; however, as children are a vulnerable population for research, caution must be taken. Additionally, hospitals offering pediatric bariatric surgery should be well-equipped and experienced in evaluating pediatric candidates using a "multidisciplinary team". ${ }^{57(p 593)}$

Veracity, or truthfulness, is an essential element of communication between patients, families, and doctors and is imperative to the decision-making process when choosing the best treatment option for the obese child. "Honesty, full disclosure, and transparency will be essential in preserving the patient and family trust in the pediatric surgeon." ${ }^{2(p 190)}$ While it is difficult to imagine why any medical team member would not be authentic and forthcoming with patients, there are some issues that could complicate this principle. For instance, higher rates of obesity lead to more bariatric surgeries and a higher consumption of medication, to counter obesity and also treat its comorbid conditions. From an economic standpoint, obesity is profitable for the professionals who treat it; therefore, monetary gain could conflict with veracity, if professionals refer children to medical interventions without absolute necessity. Lastly, within the conversation of honesty, there should be frank discussions among all the stakeholders as to the true motivation for the child's weight loss. It should not be assumed on the part of the medical professionals that the parents and/or child is primarily focused on improved health. If the intervention is being selected to alleviate parental guilt or as further discrimination of the obese child to conform to societal norms, then further attention is necessary to fully address the psychosocial needs of the patient and family, which cannot be resolved solely with medical intercessions.

\section{Obesity as abuse/neglect}

Obesogenic environments, which include the caregiver's ability to parent, as well as make sound decisions, indicate another area of concern for the obese child and are, ${ }^{65}$ in some communities, being considered a form of child abuse and/or neglect due to persistent lack of exercise, as well as overnourishment. ${ }^{65-67}$ According to the Child Abuse Prevention and Treatment Act of 2010, ${ }^{68}$ abuse is "any recent act or failure to act on the part of a parent or caretaker, which results in death, serious physical or emotional harm, sexual 
abuse or exploitation, or an act or failure to act which presents an imminent risk of serious harm" ${ }^{68(\mathrm{p} 6)}$ Legally, child abuse is one or more behaviors or an extensive lack of action that results in damage to a child or puts a child at risk of injury. Given these definitions, there is reason to conceptualize childhood obesity as maltreatment on the part of the parents. Severe or chronic abuse/neglect can lead to the involuntary termination of parental rights, as well as criminal charges. In 2008, the Child Welfare League of America reported that many state courts have expanded their definition of medical neglect to include morbid obesity and then ruled that certain children were victims of neglect because of their obesity. While some child health advocates support such decisions, others do not theorize childhood obesity as intentional or unintended harm to the child by the parent. ${ }^{69}$

All parents have inherent rights as to how they choose to raise their children. They also have social and legal obligations to provide a healthy environment in which their child can live. Parents of obese children are inadvertently categorized by at least one of three situations: they have failed to seek treatment for their child's obesity-related concerns, they have not provided the advised medical care for the child, or they have been unable or unwilling to regulate their child's behavior in an effort to decrease weight gain and the comorbid medical complications, thus creating an obesogenic environment, constituting medical neglect. ${ }^{13,66}$

The notion that parents who create and/or maintain an obesogenic home environment for the obese child are liable of child abuse/neglect is controversial in many ways. For example, who is primarily responsible for the school environment and is it also fostering obesity? As parents of obese children continue to be investigated for child abuse/neglect, more children are being removed from the home, which is known to cause emotional harm and familial damage, ${ }^{66,67}$ neither of which has been shown to reduce adiposity. Less intrusive measures to ensure child safety are available and may be optimal for some families, such as in-home services, education, and counseling. ${ }^{13,66,67}$

\section{Selecting the best treatment}

Managing the decision-making process in the treatment of childhood obesity is a difficult task with limited options available and both positive and negative aspects of each choice. Largely, this duty is placed on the parents, who must decide what is advantageous for their individual child. Ideally, parents will seek out qualified and experienced professionals to inquire about weight loss programs for their child and develop a sound understanding of the risks and benefits of each. As parents are educated on these treatment options, incorporating the obese child's perspective would be beneficial. Parents, in collaboration with helping professionals, can assess the child's ability to understand what is being considered and motivation for treatment, as well as his/her "cognitive, social, and emotional development". 2(p10) As previously discussed, many parents are acting in the best interest of their child; therefore, they must consider the danger posed by not intervening, the feasibility of treatment at this time for the child and/or family, how long the intervention will take, and what immediate and long-term effects are possible. If the child is given the opportunity to join in this process, at a developmentally appropriate level, a vested interest in the treatment and a sense of empowerment can be established within the child. Also, participation in the decision-making process confirms assent and that the child is making a choice that is deliberate and informed. ${ }^{2}$ Should the child regret the intervention later in life, especially a permanent one, the parents could be solely blamed if the child was not consulted at the time. ${ }^{21}$ It is vital that families are allowed an ample amount of time to make these important decisions and that families, as well as the multidisciplinary team, agree on the best course of treatment. One other factor for families to consider is each person's expectations for success. The obese child, parent, physician, surgeon, and family-based interventionist may all have different attitudes and outlooks regarding the outcome of the intervention. For example, Caniano ${ }^{62}$ reports that some patients and families may have an "overly optimist view of bariatric surgery ... [which] may interfere with a deep understanding of the operative risks ... [and] its irreversible nature". ${ }^{62(\mathrm{p} 188)}$ This would be an essential conversation to have before, rather than after, a treatment option is chosen.

In conclusion, while childhood obesity continues to be a physical, emotional, and psychosocial issue impacting many families, there are limited treatment options available. These choices come with their own set of risks, benefits, costs, and availability to the average American household. Treatment modalities like pharmacotherapy, family-based treatment, and bariatric surgery may resolve one problem while creating others. However, a lack of longitudinal research for some of these interventions may be at least partially responsible. As more options emerge in the treatment of childhood obesity and as evidence-based research in the field continues, children, parents, caregivers, and health care providers will be even better equipped to make sound, ethical decisions in the best interest of the obese child in an effort to not only enhance their physical health but also their quality of life. 


\section{Disclosure}

The authors declare no conflicts of interest.

\section{References}

1. Ogden CL, Carroll MD, Kit BK, Flegal KM. Prevalence of childhood and adult obesity in the United States, 2011-2012. JAMA. 2014;311(8): 806-814.

2. Inge TH, Xanthakos SA, Zeller MH. Bariatric surgery for pediatric extreme obesity: now or later? Int J Obes (Lond). 2007;31(1):1-14.

3. Halfon N, Larson K, Slusser W. Associations between obesity and comorbid mental health, developmental, and physical health conditions in a nationally representative sample of US children aged 10 to 17. Acad Pediatr. 2013;13(1):6-13.

4. Mission Readiness. Still Too Fat to Fight; 2014. Available from: http:// missionreadiness.s3.amazonaws.com/wp-content/uploads/Still-TooFat-To-Fight-Report.pdf. Accessed November 30, 2014.

5. Inge TH, Krebs NF, Garcia VF, et al. Bariatric surgery for severely overweight adolescents: concerns and recommendations. Pediatrics. 2004;114(1):217-223.

6. Capella JF, Capella RF. Bariatric surgery in adolescence. Is this the best age to operate? Obes Surg. 2003;13(6):826-832.

7. Daniels SR. Complications of obesity in children and adolescents. Int J Obes (Lond). 2009;33(1):S60-S65.

8. May AL, Kuklina EV, Yoon PW. Prevalence of cardiovascular disease risk factors among US adolescents, 1999-2008. Pediatrics. 2012; 129(6):1035-1041.

9. Pompili M, Girardi P, Tatarelli G, Ruberto A, Tatarelli R. Suicide and attempted suicide in eating disorders, obesity and weight-image concern. Eat Behav. 2006;7(4):384-394.

10. Testa MA, Simonson DC. Assessment of quality-of-life outcomes. N Engl J Med. 1996;334(13):835-840.

11. Schwimmer JB, Burwinkle TM, Varni JW. Health-related quality of life of severely obese children and adolescents. JAMA. 2003;289(14): 1813-1819.

12. Russell-Mayhew S, McVey G, Bardick A, Ireland A. Mental health, wellness, and childhood overweight/obesity. J Obes. 2012;2012:281801.

13. Varness T, Allen DB, Carrel AL, Fost N. Childhood obesity and medical neglect. Pediatrics. 2009;123(1):399-406.

14. Koukourikos K, Lavdaniti M, Avramika M. An overview on childhood obesity. Prog Health Sci. 2013;3(1):128-133.

15. Stang J, Loth KA. Parenting style and child feeding practices: potential mitigating factors in the etiology of childhood obesity. JAm Diet Assoc. 2011;111(9):1301-1305.

16. Spruijt-Metz D. Etiology, treatment, and prevention of obesity in childhood and adolescence: a decade in review. J Res Adolesc. 2011;21(1): 129-152.

17. Xu F, Chepyator-Thomson JR, Culp B. School-based physical education programs and obesity in the United States: trends, rationalizations, and perspectives of change. Edu Res J. 2010;25(2):242-261.

18. Berge JM, Rowley S, Trofholz A, et al. Childhood obesity and interpersonal dynamics during family meals. Pediatrics. 2014;134(5): 923-932.

19. Huerta M, Gdalevich M, Tlashadze A, et al. Appropriateness of US and international BMI-for-age reference curves in defining adiposity among Israeli school children. Eur J Pediartr. 2007;166(6):573-578.

20. Kuczmarski RJ, Ogden CL, Grummer-Strawn LM, et al. CDC growth charts: United States. Adv Data. 2000;8(314):1-27.

21. Hofmann B. Bariatric surgery for obese children and adolescents: a review of the moral challenges. BMC Med Ethics. 2013;14:18.

22. Hoyt CL, Burnette JL, Auster-Gussman L. "Obesity is a disease": examining the self-regulatory impact of this public-health message. Psychol Sci. 2014;25(4):997-1002.

23. Allison DB, Downey M, Atkinson RL, et al. Obesity as a disease: a white paper on evidence and arguments commissioned by the council of the obesity society. Obesity. 2008;16(6):1161-1177.
24. De Godoy-Matos AF, Guedes EP, de Souza LL, Martins MF. Management of obesity in adolescents: state of art. Arq Bras Endocrinol Metabol. 2009;53(2):252-261.

25. Diaz EG, Folgueras TM. Systematic review of the clinical efficacy of sibutramine and orlistat in weight loss, quality of life and its adverse effects in obese adolescents. Nutr Hosp. 2011;26(3):451-457.

26. Dolinsky DH, Armstrong SC, Kinra S. The clinical treatment of childhood obesity. Indian J Pediatr. 2013;80(1):S48-S54.

27. Whitlock EP, O'ConnerEA, Williams SB, Beil TL, Lutz KW. Effectiveness of weight management interventions in children: a targeted systematic review for the USPSTF. Pediatrics. 2010;125(2):e396-e418.

28. Hearnshaw C, Matyka K. Managing childhood obesity: when lifestyle change is not enough. Diabetes Obes Metab. 2010;12(11):947-957.

29. Muller A, Mitchell JE, Sondag C, de Zwaan M. Psychiatric aspects of bariatric surgery. Curr Psychiatry Rep. 2013;15(10):397.

30. Suzuki J, Haimovici F, Chang G. Alcohol use disorders after bariatric surgery. Obes Surg. 2012;22(2):201-207.

31. Rogovik AL, Chanoine J-P, Goldman RD. Pharmacotherapy and weight-loss supplements for treatment of paediatric obesity. Drugs. 2010;70(3):335-346.

32. Yu CC, Li AM, Chan KO, et al. Orlistat improves endothelial function in obese adolescents: a randomized trial. J Paediatr Child Health. 2013;49(11):969-975.

33. Chanoine JP, Richard M. Early weight loss and outcome at one year in obese adolescents treated with orlistat or placebo. Int J Pediatr Obes. 2011;6(2):95-101.

34. Patham B, Mukherjee D, San Juan ZT. Contemporary review of drugs used to treat obesity. Cardiovasc Hematol Agents Med Chem. 2013;11(4):272-280.

35. Baur LA, Hazelton B, Shrewsbury VA. Assessment and management of obesity in childhood and adolescence. Nat Rev Gastroenterol Hepatol. 2011;8(11):635-645.

36. Levine MD, Ringham RM, Kalarchian MA, Wisniewski L, Marcus MD. Is family-based behavioral weight control appropriate for severe pediatric obesity? Int J Eat Disord. 2001;30(3):318-328.

37. Perryman ML. Ethical family interventions for childhood obesity. Prev Chronic Dis. 2011;8(5):A99.

38. Sung-Chan P, Sung YW, Zhao X, Brownson RC. Family-based models for childhood-obesity intervention: a systematic review of randomized controlled trials. Obes Rev. 2013;14(4):265-278.

39. Perryman ML, Nielsen S, Booth J. An Examination of the Family's Role in Childhood Obesity. Alexandria, VA: Vistas Online, American Counseling Association; 2008.

40. Kalarchian MA, Levine MD, Arslanian SA, et al. Family-based treatment of severe pediatric obesity: a randomized controlled trial. Pediatrics. 2009;124(4):1060-1068.

41. Kelleher DC, Merrill CT, Cottrell LT, Nadler EP, Burd RS. Recent national trends in the use of adolescent inpatient bariatric surgery: 2000 through 2009. JAMA Pediatr. 2013;167(2):126-132.

42. Schilling PL, Davis MM, Albanese CT, Dutta S, Morton J. National trends in adolescent bariatric surgical procedures and implications for surgical centers of excellence. J Am Coll Surg. 2008;206(1):1-12.

43. Zwintscher NP, Azarow KS, Horton JD, Newton CR, Martin MJ. The increasing incidence of adolescent bariatric surgery. J Pediatr Surg. 2013;48(12):2401-2407.

44. Jen HC, Rickard DG, Shew SB, et al. Trends and outcomes of adolescent bariatric surgery in California, 2005-2007. Pediatrics. 2010;126(4): e746-e753.

45. Pallati P, Buettner S, Simorov A, Meyer D, Shaligram A, Oleynikov D. Trends in adolescent bariatric surgery evaluated by UHC database collection. Surg Endosc. 2012;26(11):3077-3081.

46. Algahtani AR, Antonisamy B, Alamri H, Elahmedi M, Zimmerman VA. Laparoscopic sleeve gastrectomy in 108 obese children and adolescents aged 5 to 21 years. Ann Surg. 2012;256(2):266-273.

47. Pratt JS, Lenders CM, Dionne EA, et al. Best practice updates for pediatric/adolescent weight loss surgery. Obesity (Silver Spring). 2009; 17(5):901-910. 
48. Inge $\mathrm{TH}$. Bariatric surgery for morbidly obese adolescents: is there a rationale for early intervention? Growth Horm IGF Res. 2006;16(A): S15-S19.

49. Garcia VF, DeMaria EJ. Adolescent bariatric surgery: treatment delayed, treatment denied, a crisis invited. Obes Surg. 2006;16(1):1-4.

50. Tindle HA, Omalu B, Courcoulas A, Marcus M, Hammers J, Kuller LH. Risk of suicide after long-term follow-up from bariatric surgery. Am J Med. 2010;123(11):1036-1042.

51. Groven KS, Raheim M, Engelsrud G. "My quality of life is worse compared to my earlier life": living with chronic problems after weight loss surgery. Int J Qual Stud Health Well Being. 2010;5(4):5553.

52. Golomb BA, Koperski S. Pondering the ponderous: are the "moral challenges" of bariatric surgery morally challenged? Am J Bioeth. 2010;10(12):24-26.

53. Ogden J, Flanagan Z. Beliefs about the causes and solutions to obesity: a comparison of GPs and lay people. Patient Educ Couns. 2008;71(1): $72-78$.

54. van Geelan SM, Bolt IL, van der Baan-Slootweg OH, van Summeren MJ. The controversy over pediatric bariatric surgery: an explorative study on attitudes and normative beliefs of specialists, parents, and adolescents with obesity. J Bioeth Inq. 2013;10(2):227-237.

55. Woolford SJ, Clark SJ, Gebremariam A, Davis MM, Freed GL. To cut or not to cut: physicians' perspectives on referring adolescents for bariatric surgery. Obes Surg. 2010;20(7):937-942.

56. Iqbal CW, Kumar S, Iqbal AD, Ishitani MB. Perspectives on pediatric bariatric surgery: identifying barriers to referral. Surg Obes Relat Dis. 2009;5(1):88-93.

57. Buchwald H. Bariatric surgery for morbid obesity: health implications for patients, health professionals, and third-party payers. J Am Coll Surg. 2005;200(4):593-604.

58. Gallagher SM. What is the meaning of informed consent, weight loss surgery, and the pediatric patient? Bariatr Nurs Surg Patient Care. 2010;5(3):231-234.
59. Zeller MH, Guilfoyle SM, Reiter-Purtill J, Ratcliff MB, Inge TH, Long JD. Adolescent bariatric surgery: caregiver and family functioning across the first postoperative year. Surg Obes Relat Dis. 2011;7(2):145-150.

60. Cromley TR, Neumark-Sztainer D, Story M, Boutelle K. Parent and family associations with weight-related behaviors and cognitions among overweight adolescents. J Adolesc Health. 2010;47(3):263-269.

61. Kitchener KS. Intuition, critical evaluation and ethical principles: the foundation for ethical decisions in counseling psychology. Couns Psychol. 1984;12(3):43-55.

62. Caniano DA. Ethical issues in pediatric bariatric surgery. Semin Pediatr Surg. 2009;18(3):186-192.

63. Van Allen J, Kuhl ES, Filigno SS, Clifford LM, Connor JM, Stark LJ. Changes in parent motivation predicts changes in body mass index z-score (zBMI) and dietary intake among preschoolers enrolled in a family-based obesity intervention. J Pediatr Psychol. 2014;39(9): 1028-1037.

64. Hunter HL, Steele RG, Steele MM. Family based treatment for pediatric overweight: parental weight loss as a predictor of children's treatment success. Child Health Care. 2008;37(2):112-125.

65. Maglo KN, Martin LJ. Researching vs reifying race: the case of obesity research. Humanamente. 2012;22:111-143.

66. Murtagh L, Ludwig DS. State intervention in life-threatening childhood obesity. JAMA. 2011;306(2):206-207.

67. Goldbas A. Childhood obesity: can it really be child neglect? Int $J$ Childbirth Educ. 2014;29(2):37-40.

68. The Child Abuse Prevention and Treatment Act (CAPTA) 2010. Children's Bureau: An Office of the Administration for Children and Families; 2011. Available from: http://www.acf.hhs.gov/programs/cb/ resource/capta2010. Accessed January 19, 2015.

69. Child Welfare League of America. Childhood obesity: is it abuse? Child Voice. 2008;17:4.
Medicolegal and Bioethics

\section{Publish your work in this journal}

Medicolegal and Bioethics is an international, peer-reviewed, open access journal exploring the application of law to medical and drug research and practice and the related ethical and moral considerations. The journal is characterized by the rapid reporting of reviews, case reports, guidelines and consensus statements, original research

\section{Dovepress}

and surveys. The manuscript management system is completely online and includes a very quick and fair peer-review system. Visit http://www.dovepress.com/testimonials.php to read real quotes from published authors. 